\title{
ANÁLISE DA FOLKSONOMIA EM GRUPOS COLABORATIVOS DO PASSEI DIRETO
}

\author{
Jéssica Pereira de Oliveira ${ }^{1}$ \\ Universidade Federal de Pernambuco \\ jessica.pdo@live.com \\ Fabio Assis Pinho \\ Universidade Federal de Pernambuco \\ fabiopinho@ufpe.br
}

\begin{abstract}
Resumo
Este artigo é sobre a folksonomia como uma ferramenta que contribui para as atividades colaborativas de grupos de usuários na rede social acadêmica Passei Direto, com o objetivo de analisar a folksonomia como ferramenta de apoio em grupos colaborativos nessa rede social, por meio de estudo de caso holístico e exploratório, sendo realizada observação direta intensiva. A justificativa baseou-se na necessidade de compreender a potencialidade das atividades cooperativas e a solução das necessidades informacionais. Concluiu-se que a folksonomia é uma ferramenta de apoio em grupos colaborativos no Passei Direto, onde os usuários, no uso de tags em práticas de indexação, visam a enriquecer e ampliar as possibilidades de acesso às informações. No entanto, apesar de representar uma ferramenta de forte cunho colaborativo, a folksonomia também deixa lacunas no tocante à recuperação da informação, dada a falta de padronização e controle dessa ferramenta, embora essas características façam parte da sua essência.
\end{abstract}

Palavras-chave: Folksonomia. Indexação Social. Organização do Conhecimento. Grupos Colaborativos.

\section{ANALYSIS OF FOLKSONOMY IN COLLABORATIVE GROUPS OF PASSEI DIRETO}

\begin{abstract}
This paper is about folksonomy as a tool that contributes to the collaborative activities of user groups in the academic social network Passei Direto, with the aim of analyzing folksonomy as a support tool in collaborative groups in this social network, through a case study holistic and exploratory, with intensive direct observation. The justification was based on the need to understand the potential of cooperative activities and the solution of informational needs. It was concluded that folksonomy is a support tool in collaborative groups in Passei Direto, where users, in the use of tags in indexing practices, aim to enrich and expand the possibilities of access to information. However, despite representing a tool of strong collaborative nature, folksonomy also leaves gaps regarding information retrieval, given the lack of standardization and control of this tool, although these characteristics are part of its essence.
\end{abstract}

Keywords: Folksonomy. Social Indexing. Knowledge Organization. Collaborative Grou165p.

\footnotetext{
${ }^{1}$ Mestra em Ciência da Informação e Bacharela em Biblioteconomia, ambas, pela UFPE.

${ }^{2}$ Doutor e Mestre em Ciência da Informação pela UNESP. Bacharel em Biblioteconomia e Ciência da Informação pela UFSCar. Professor e Pesquisador na UFPE. 


\section{INTRODUÇÃO}

A colaboração é a característica primordial dessas novas práticas informacionais que podem ser observadas nos ambientes virtuais, as quais são materializadas quando os indivíduos buscam informações ou reúnem-se em comunidades que possuem interesses e necessidades informacionais semelhantes (SECO; SANTOS; BARTALO, 2016).

Desse modo, uma das formas de colaboração entre os indivíduos em ambientes virtuais é o uso da folksonomia. A folksonomia, por meio da linguagem natural, é uma forma de personalizar a representação e recuperação de conteúdos na web. É uma linguagem popular gerada, compartilhada e fortalecida pelo ambiente colaborativo propiciado pelas redes sociais, e o sucesso desse tipo de rede consiste em ter uma participação sustentável dos usuários.

O gerenciamento das informações é interativo e permite que os usuários classifiquem suas publicações por intermédio da atribuição de termos que "destacam-se de formas mais ou menos intensas, dependendo do site e do objeto informacional, o que é justificado pelo objetivo de cada serviço virtual que emprega este recurso" (SANTOS, 2013, p. 96). Esses termos, além de representar as informações, também as organizam e fomentam grupos de usuários em torno de uma temática específica, proporcionando a sua interatividade.

O Passei Direto é uma plataforma de estudos para universitários que foi concebida para permitir que os usuários pudessem compartilhar seus próprios materiais, tais como anotações, resumos, listas de exercícios, trabalhos etc., com o intuito de auxiliar os estudantes nos estudos. Para além do conteúdo colaborativo enviado por estudantes, há também conteúdo próprio do Passei Direto, criado por especialistas, como soluções passo a passo de exercícios, videoaulas e resumos (PASSEI DIRETO, c2021).

O Passei Direto foi desenvolvido por dois estudantes da PUC-Rio: Rodrigo Salvador e André Simões, com a intenção de facilitar a troca de conhecimento entre universitários, através de uma plataforma desenvolvida com o objetivo de ampliar o poder de estudo dos estudantes através da tecnologia. Hoje, a equipe do Passei Direto conta com mais de 40 profissionais em diversas áreas, como Cultura, Tecnologia, Dados, Design, Marketing, Conteúdo etc. (PASSEI DIRETO, c2021). A plataforma é considerada uma das redes mais populares com esse foco, onde o número de usuários e publicações é crescente desde o seu surgimento.

Enquanto rede social acadêmica, o Passei Direto oferece o serviço de Biblioteca Digital, uma vez que reúne documentos - formando coleções de documentos digitais - e oferece meios de inserção, busca e recuperação da informação, além da possibilidade de personalização do serviço, de forma a prover a colaboratividade e a interação entre os seus usuários. 
Nesse contexto, surge a questão de pesquisa que aqui se postula: a folksonomia é uma ferramenta de apoio em grupos colaborativos no Passei Direto?

A principal hipótese que se levanta é a de que o uso da folksonomia, além de cumprir os propósitos de organização e representação, propicia o desenvolvimento das atividades de grupos colaborativos, à medida que os usuários a utilizam para potencializar suas atividades cooperativas e solucionar suas necessidades informacionais no Passei Direto.

Justifica-se este estudo dado que a folksonomia propõe uma tentativa de buscar um cenário mais amplo diante da imposição do mundo digital e intercultural por meio de um "posicionamento ético sensível às necessidades de conhecimento das mais diversas vozes sociais, a partir de uma atuação que respeite a diversidade e o pluralismo lógico e cultural" (ARBOIT, 2014, p. 383) e prospera em ambientes virtuais, por ser uma ferramenta popular orientada por uma pragmática contextual, e não unívoca, como defende García Gutiérrez (2011), este estudo se fez pertinente no âmbito da Ciência da Informação.

Além disso, uma vez que a recuperação da informação não pode trabalhar eficientemente sem o que é aprendido sobre organização e representação do conhecimento (SMIRAGLIA, 2014), a compreensão da folksonomia enquanto ferramenta que organiza, representa e recupera informações é fundamental para o bom funcionamento da Ciência da Informação nos ambientes e redes sociais virtuais.

É importante ter a percepção de que os usuários estão propondo novos arranjos para organizar e recuperar informações em rede, impulsionados por uma visão cosmopolita e colaborativa, em concordância com García Gutiérrez (2011) que sugere que a organização do conhecimento e da memória registrada deveria ser reapropriada a partir do pluralismo lógico e usos culturais desinentes das necessidades dos grupos.

Desta forma, o objetivo geral desta pesquisa foi analisar a folksonomia como ferramenta de apoio em grupos colaborativos no Passei Direto.

\section{FOLKSONOMIA: MÉTODO DE CLASSIFICAÇÃO SOCIAL}

Existem diversos tipos de sistemas de classificação e não há apenas um sistema em vigor, o que há é a convivência entre alguns sistemas classificatórios. Há os sistemas menos complexos e simplistas (como aqueles baseados em dicotomias) e há os mais complexos e refinados na percepção das coisas, nos quais os agrupamentos (categorias e subcategorias) vão se tornando mais específicos (ARAÚJO, 2006). 
Smiraglia (2014) elucida que as classificações devem ser sistemáticas, o que significa que deve haver regras de inclusão e exclusão que sejam facilmente compreensíveis e aplicáveis. Elas também devem ser flexíveis e expansíveis, o que significa que, à medida que novas entidades são descobertas, deve haver espaço para elas e regras que permitam que elas sejam incorporadas.

Por conseguinte, não há como falar sobre classificação sem falar sobre taxonomia. No contexto da Ciência da Informação, as taxonomias são estruturas classificatórias hierárquicas de uma determinada área do conhecimento que têm por objetivo servir como instrumento para organizar, representar e recuperar informações - segundo uma ordem lógica, apoiada em princípios classificatórios que pressupõe uma relação entre os termos e os conceitos (CAMPOS; GOMES, 2007).

Smiraglia (2014) explica que uma taxonomia é uma lista ordenada de termos juntamente com suas definições e/ou outras características determinantes, com certos tipos de relacionamentos, tendo seus conceitos organizados em ordens hierárquicas. A forma e o conteúdo de qualquer taxonomia dependem da epistemologia do domínio para o qual ela foi desenvolvida (DÍAZ PIRAQUIVE; JOYANES AGUILAR; MEDINA GARCÍA, 2009).

Assim, compreende-se que não existe uma taxonomia certa ou errada, mas sim uma taxonomia que é organizada a partir de um determinado ponto de vista, que entende uma dada realidade e pode atender a diversos propósitos; a taxonomia não é neutra, mas deve ser consistente e relevante.

Na Ciência da Informação, além de classificarmos para agrupar, também classificamos para representar. Representar um documento é como reapresentá-lo ou apresentá-lo de forma diferente, sem perder seu valor e significado (VIGNOLI; ALMEIDA; CATARINO, 2014).

Além disso, os usuários desenvolveram práticas de classificação social dentro de sistemas e plataformas, como a adoção de um conjunto de termos para classificar os conteúdos informacionais de acordo com determinados assuntos de seu interesse. E por ser uma tarefa distribuída entre os inúmeros usuários de um serviço que não segue uma única diretriz orientando a representação dos conteúdos, a classificação social é atualmente um dos métodos mais populares para acesso e recuperação em ambientes digitais/virtuais.

Nesse sentido, surge a folksonomia como o resultado da atribuição livre e pessoal de termos/palavras-chave (tags, etiquetas) aos documentos, que se origina das ações de indexação desempenhadas por usuários, com o objetivo de agrupar/classificar informações para posterior recuperação (CATARINO; BAPTISTA, 2009). 
A folksonomia evidencia a categorização colaborativa por meio do uso de tags, sem hierarquias predeterminadas, sem categorias fixas ou relações de parentesco, como tradicionalmente se faz, mas por meio dos termos adicionados e gerenciados livremente pelas pessoas que usam os sistemas e plataformas. Assim, é uma prática que ocorre em ambientes virtuais compartilhados, dada a sua natureza colaborativa, onde as decisões de etiquetagem são tomadas pelos próprios usuários, permitindo o uso de várias tags - e até mesmo categorias para classificar um mesmo documento (DÍAZ PIRAQUIVE; JOYANES AGUILAR; MEDINA GARCÍA, 2009).

Então, a folksonomia pode ser compreendida como uma classificação popular que se origina das ações de representação da informação desempenhadas por usuários. Representar tematicamente um documento é garantir que ele possa ser recuperado mediante elaboração de estratégias de busca. Isso pode ser aplicado tanto na representação formal da informação quanto na informal, na utilização de termos desenvolvidos por usuários em ambiente virtual, como em folksonomias, por meio das tags (VIGNOLI; ALMEIDA; CATARINO, 2014).

Como explica Strehl (2011), esses novos instrumentos não apenas ampliaram as possibilidades de indexação e recuperação dos documentos, mas também transformaram a forma de navegação na web, tornando-a uma experiência social, visto que "traz o sujeito informacional para o núcleo da discussão e permite conceber a validação terminológica e as dinâmicas da linguagem como o resultado das práticas colaborativas voltadas às ações de representação da informação" (ASSIS; MOURA, 2013, p. 102).

Em outras palavras, a folksonomia é uma indexação dinâmica em linguagem natural, não havendo regras e/ou política de indexação, logo, não há controle de vocabulário nem tradução dos termos para uma linguagem artificial (CATARINO; BAPTISTA, 2009). As etiquetas representam uma forma não hierárquica de organização, já que as informações são localizadas por meio de correlações associativas e inferências - tags que remetem a outras tags.

Para Viera e Garrido (2011), a folksonomia (classificação social, etiquetagem colaborativa ou social) representa uma mudança fundamental, visto que não é derivada apenas de profissionais ou criadores de conteúdos, mas de usuários de informações e documentos, podendo ser definida como um sistema de organização ou categorização social de muitos para muitos. Dessa forma, a folksonomia permite a geração de dados produzidos pela participação de milhares de usuários; e esse sistema colaborativo usado por muitos sites e redes sociais virtuais materializa a arquitetura da participação, bem como a ideia de inteligência coletiva (DÍAZ PIRAQUIVE; JOYANES AGUILAR; MEDINA GARCÍA, 2009). 
Portanto, a folksonomia pode ser explicada como "um processo pelo qual uma massa distribuída de usuários aplica palavras-chave a vários tipos de fontes de informação da web para propósitos de organização colaborativa da informação e recuperação" (TAYLOR; JOUDREY, 2009 , p. 364). A folksonomia tanto pode ser uma categorização totalmente baseada naquilo que as pessoas consideram significativo sobre alguma coisa, quanto pode ser um sistema de organização que realiza sua própria gestão de informações ou também um software social (VIERA; GARRIDO, 2011).

Nesse sentido, quando os próprios usuários, através de ferramentas cooperativas, organizam a informação para que possam recuperá-la por meio de uma busca apoiada por conexões e significados, constata-se uma eventual mudança nos padrões organizacionais das informações em rede (SANTOS, 2013). Assim, as folksonomias promovem uma cultura de colaboração à medida que os usuários compartilham e apropriam-se de informações, e muitas são as comunidades favorecidas com essa prática, desde que conseguiram classificar e organizar conteúdos que contribuem para a geração de novos conhecimentos em rede (DÍAZ PIRAQUIVE; JOYANES AGUILAR; MEDINA GARCÍA, 2009).

É interessante observar como as folksonomias rompem com as teorias clássicas da construção do conhecimento, porque embora as folksonomias não apresentem relações formais ou outras relações hierárquicas, elas naturalmente estabelecem relações que, de alguma forma, contribuem para a geração de conhecimento, na medida em que compartilham e organizam informações por tópicos relacionados (DÍAZ PIRAQUIVE; JOYANES AGUILAR; MEDINA GARCÍA, 2009).

As múltiplas expressões de conteúdo publicadas nesses sistemas têm sido especialmente interessantes para a criação de uma representação da realidade que é espontaneamente articulada por meio das categorias e tags construídas pelos próprios usuários, com base em seus gostos, preferências, temas, tendências e grupos. Tudo isso permite a identificação das características dos diferentes domínios de usuários que interagem nessas plataformas (PÉREZ SANCHIDRIÁN; CAMPOS POSADA, R.; CAMPOS POSADA; G., 2014).

Nesse sentido, Bullard (2018) explica que a folksonomia começa com a premissa de que a descrição e a recuperação são o trabalho cumulativo de um grande conjunto distribuído de indivíduos, envolvendo elementos de colaboração e trabalho em equipe. Enquanto alguns elementos dos Sistemas de Organização do Conhecimento tradicionais representam a evitabilidade de campos abertos, essa é a premissa de um sistema de tags: o usuário não terá que consultar ou ser limitado por um conjunto de termos predefinidos. 
A folksonomia está em constante crescimento e é cada vez mais utilizada por todos os tipos de usuários, uma vez que não é necessário ter conhecimento especializado de sistemas de classificação, pois ela responde ao objetivo para o qual surgiu: a simples organização dos recursos da web (DÍAZ PIRAQUIVE; JOYANES AGUILAR; MEDINA GARCÍA, 2009).

É importante ressaltar que as tags não são resultado apenas de uma diversidade de formas de expressão permitidas pela linguagem, pois, como explica Santos (2013, p. 97), elas "provêm, também, de uma imensidão de significados que podem ser atribuídos a um mesmo documento por diferentes indivíduos provenientes de inúmeros contextos", logo, existem formas variadas de representação para um único conceito.

Sobre isso, García Gutiérrez (2011) explica que um conceito pode ter vários sentidos, decorrentes da influência que os diversos contextos sociais, culturais, históricos e locais exercem na sua formulação, uso e transformação. Assim, para o autor, um conceito não pode ser unívoco, além de não ser capaz de absorver e petrificar a dinâmica da realidade.

\section{GRUPOS COLABORATIVOS E COMPARTILHAMENTO DE INFORMAÇÕES}

Para os indivíduos, as comunidades virtuais representam "um canal de entretenimento, suporte, apoio, reflexão e trocas de informações em suas relações" (SECO; SANTOS; BARTALO, 2016, p. 57) e são um ambiente onde são estimulados a compartilhar informações e ajudar outros indivíduos, estimulando a transmissão de conhecimento a partir das trocas de experiências vivenciadas.

Assim, o compartilhamento pode ser visto como uma cultura de interação social que se desenvolve por meio de ações baseadas nas habilidades individuais que estimulam o desenvolvimento de ações conjuntas que fortaleçam a construção do coletivo (TOMÁEL; MARTELETO, 2006).

Nesse sentido, Marteleto (2005) explica que as redes sociais incorporam três dimensões fundamentais, são elas: a) dimensão sócio-comunicacional: envolve os elos, as motivações e as interações entre os atores sociais; b) linguístico-discursiva: compreende os aspectos cognitivos e informacionais envolvidos no compartilhamento social; c) produção de sentidos: evidencia a dinâmica e o fluxo da ação colaborativa.

Nessa perspectiva, para a existência, manutenção e crescimento dessas redes e comunidades que buscam interação e colaboração é imprescindível o ato de compartilhar informações. Compartilhar significa participar, compartir e partilhar (SECO; SANTOS; BARTALO, 2016) e é uma atividade essencial para melhorar o desenvolvimento das redes, 
podendo ocorrer tanto por processos individuais quanto por coletivos, onde um processo tem influência sobre o outro (TOMAÉL; MARTELETO, 2006).

Tomáel e Marteleto (2006, p. 2) explicam que “o conhecimento de um indivíduo, quando em interação com o conhecimento de outros indivíduos, resulta em novos conhecimentos individuais e, em alguns domínios, coletivos”. Desse modo, o compartilhamento pode ser visto como uma cultura de interação social que se desenvolve por meio de ações baseadas nas habilidades individuais que estimulam o desenvolvimento de ações conjuntas que fortaleçam a construção do coletivo (TOMÁEL; MARTELETO, 2006). Assim, ao compartilhar, os indivíduos aprendem com a experiência adquirida nas relações que fortalecem e aprimoram o desenvolvimento.

Destarte, "com base no compartilhamento, o conhecimento deixa de ser parte e começa a ser todo, a ser coletivo" (TOMÁEL; MARTELETO, 2006, p. 4), envolvendo as atividades de um grupo de indivíduos que possuem uma multiplicidade de interesses e valores construídos nas redes sociais que influenciam o compartilhamento de informações (SECO; SANTOS; BARTALO, 2016). Então, essa participação na rede é muito rica e deve ser constantemente estimulada, para que as relações dos sujeitos em favor de um grupo possam se fortalecer.

Para subsistir, o compartilhamento de informações necessita da participação mútua dos indivíduos, os quais, através dos meios de comunicação, se integram em uma relação comunicativa para gerenciar o fluxo informacional dentro da rede. As redes de informação e comunicação contribuem para que o fluxo de interação seja eficiente e dinâmico, uma vez que facilitam a comunicação entre os sujeitos (AMORIM; TOMAÉL, 2011).

Alcará et al. (2009) acredita que o avanço tecnológico promoveu e aprimorou o compartilhamento de informações, especialmente nas comunidades virtuais, já que as tecnologias ofereceram a possibilidade de o compartilhamento ocorrer através de diversos canais comunicacionais.

Qin (2008) defende que esses novos ambientes podem ser vistos como espaços sociais semânticos onde são identificadas comunidades virtuais que se organizam em torno do compartilhamento de informações por meio de conceitos relevantes. Para o autor, esse espaço social semântico apresenta-se numa tríade circular composta pelos agentes comunicacionais humanos, uma rede de conceitos e um conjunto de tags.

Esses contextos permitem a integração de várias modalidades de comunicação em uma rede interativa no mesmo sistema, cujo conteúdo apresenta facilidades de organização, representação e recuperação por meio de ferramentas como a classificação social. Esses sistemas geralmente se desenvolvem em ambientes compartilhados que apresentam uma 
dimensão social ou coletiva onde os usuários compartilham suas tags e recursos, gerando, por colaboração implícita, um índice global de etiquetas (folksonomia), por meio do qual os usuários podem recuperar qualquer recurso descrito por outros (PÉREZ SANCHIDRIÁN; CAMPOS POSADA, R.; CAMPOS POSADA; G., 2014).

Nesse sentido, a etiquetagem pode ser considerada um ato de fazer sentido, com as tags compartilhadas se tornando uma forma de significado coletivo, uma vez que os usuários etiquetam para entender - ou organizar - uma parte do seu mundo. Quando compartilhadas com outras pessoas ou visualizadas no contexto do que outras pessoas classificaram, essas coleções de identificadores de recursos, tags e pessoas começam a ganhar valor adicional por meio de efeitos de rede. As tags de pesquisa podem permitir a descoberta de outros recursos relevantes e as relações sociais que se desenvolvem entre os marcadores se tornam um meio de descoberta de informações em si mesmas (TRANT, 2009).

Quer dizer, pela natureza flexível e dinâmica dos sistemas que envolvem a folksonomia, ela pode acelerar o movimento colaborativo em ambientes de compartilhamento de informações, devido ao fato de surgir como um meio de representação dos grupos que fazem uso dessa ferramenta de classificação social para fortalecer suas práticas de colaboração. Para Trant (2009), os incentivos ao usuário são divididos em motivações organizacionais e sociais, incluindo recuperação, contribuição e compartilhamento futuros.

Assim, a folksonomia se apresenta na interface entre usuários e informação em rede por meio de ações colaborativas para a organização, representação e compartilhamento de informações. Dentro dessa coletividade cada usuário possui suas experiências e seus conhecimentos particulares, que se somam às experiências e conhecimentos dos demais usuários e promovem a construção de uma inteligência coletiva. Quando pensamos nessas redes de relacionamentos e trocas de informações entre comunidades, compreendemos que são práticas benéficas para a sociedade, uma vez que potencializam a aprendizagem, a mobilidade social e o seu desenvolvimento, através de indivíduos comprometidos com esse propósito.

\section{PROCEDIMENTOS METODOLÓGICOS}

A pesquisa foi caracterizada como exploratória, com abordagem dialética - escolhida por compreender o mundo como um conjunto de processos, onde as coisas são analisadas na qualidade de objetos em movimento, havendo a possibilidade de se transformar e se desenvolver, uma vez que o fim de um processo pode ser o começo de outro (MARCONI; LAKATOS, 2003). 
A princípio, para analisar a folksonomia como ferramenta de apoio em grupos colaborativos no Passei Direto, foi necessário compreender a folksonomia e a colaboratividade de grupos em redes sociais virtuais (tal como o compartilhamento de informações), por meio da revisão de bibliografia. O estudo de caso holístico foi escolhido como estratégia de pesquisa.

Quanto à técnica de coleta de dados, foi realizada a observação direta intensiva (observação participante) que, segundo Marconi e Lakatos (2003), aumenta a familiaridade do pesquisador com o ambiente e com os fenômenos estudados.

O Passei Direto foi escolhido por seu caráter acadêmico associado às características e funcionamento de rede social e por incluir a folksonomia como ferramenta atuante em seu sistema, aspecto essencial para compreender a colaboratividade entre indivíduos de um grupo por meio do seu uso.

Quanto à população-alvo, os grupos do Passei Direto selecionados para análise foram escolhidos por sua relação com disciplinas associadas à Ciência da Informação, de acordo com os seguintes critérios: a) Disciplinas relacionadas com a área de Ciência da Informação; b) Disciplinas que possuem mais de 500 seguidores (membros/usuários); c) Disciplinas que possuem mais de 100 materiais compartilhados; d) Disciplinas em que o uso da folksonomia seja recorrente nas práticas de compartilhamento.

De acordo com os critérios, os grupos selecionados foram: Grupo 1 - @Ciência da Informação: esse grupo contava com pouco mais de 1.150 seguidores e cerca de 210 materiais compartilhados; Grupo 2 - @Biblioteconomia: esse grupo contava com pouco mais de 7.270 seguidores e cerca de 1.990 materiais compartilhados; Grupo 3 - @ Gestão da Informação: esse grupo contava com pouco mais de 1.330 seguidores e cerca de 520 materiais compartilhados.

A observação participante foi realizada de acordo com os seguintes critérios de análise: foram feitas anotações sobre as atividades colaborativas dos três grupos escolhidos e suas práticas de indexação por meio do uso da folksonomia.

A observação foi sistematizada da seguinte forma: as práticas de indexação, por meio do uso da folksonomia (das tags utilizadas pelos usuários para classificar os materiais), foram analisadas nos últimos 30 documentos compartilhados nos grupos, onde foi observado se a folksonomia foi utilizada nesses documentos e a quantidade de termos utilizados para indexálos - levando em conta a quantidade de termos que normalmente são utilizados nas palavraschave de trabalhos acadêmicos, de artigos científicos etc., que varia entre 3 e 5 palavras.

Os dados foram coletados no mês de novembro de 2020, referentes aos últimos 30 documentos publicados nos três grupos selecionados, analisando as tags que foram atribuídas pelos próprios usuários no compartilhamento dos materiais. Além de observar as tags pelo 
prisma quantitativo, foram feitas algumas análises a respeito das características dessas tags com intuito de atingir o objetivo desta pesquisa.

\section{ANÁLISE DOS DADOS}

Atualmente, o termo "redes sociais" designa grandes plataformas de interação virtual, tais como o Passei Direto. Assim, o seu significado está atrelado ao conceito de ambientes virtuais onde a interação entre os indivíduos é feita a partir da troca de informações nas plataformas.

Na plataforma de estudos Passei Direto os usuários podem compartilhar seus próprios materiais (como anotações, resumos, listas de exercícios, trabalhos etc.) e podem buscar por materiais compartilhados por outros usuários e/ou disponibilizados pela própria equipe da plataforma.

Além disso, nessa rede social acadêmica os usuários podem participar de grupos colaborativos virtuais, denominados disciplinas, onde ocorre o gerenciamento dos materiais/documentos que compõe as coleções desses grupos. Nesses grupos, os usuários desenvolvem suas atividades colaborativas, buscando informações e também compartilhando materiais pertinentes para o seu desenvolvimento.

Os termos descritores atribuídos aos documentos pelos próprios usuários que os inseriram na coleção de um grupo - ficam visíveis logo abaixo dos metadados de descrição física (o título do documento) e cada usuário, estando "logado" na rede, é identificado por seu nome de usuário, podendo inserir documentos nas coleções de seus grupos/disciplinas.

Entre as informações básicas a serem preenchidas encontra-se o campo "tags", que diz respeito à descrição temática dos documentos, realizada pelos usuários por meio da atribuição de termos em linguagem natural - a folksonomia. É importante pontuar que o próprio sistema sugere algumas tags à medida em que o usuário vai digitando as letras do termo que pretende utilizar.

Dessa forma, o Passei Direto exibe algumas tags já consolidados no sistema, por terem sido utilizadas anteriormente por outros usuários, as quais podem ser escolhidas pelo usuário no momento em que está realizando o seu compartilhamento. Quer dizer, por meio desse recurso do sistema o usuário sabe quais termos estão sendo utilizados pelos demais usuários, se esses termos também lhe servem ou se será mesmo necessário fazer uso de um termo que ainda não foi utilizado. 
Além disso, para realizar a busca dentro da rede o usuário também faz uso da folksonomia, uma vez que a busca é livre por quaisquer termos que o usuário considerar mais relevantes às suas necessidades informacionais. Durante uma busca, a rede identifica em suas coleções digitais todos os documentos que possuem as palavras utilizadas, seja em seu título, resumo ou tags utilizadas pelos usuários.

Desse modo, o Passei Direto é um ambiente que gera novos espaços para que os usuários interajam entre si, havendo interesses em comum. Tais interesses não envolvem apenas os documentos em si, mas essencialmente o compartilhamento de informações, que é, afinal, o propósito de se estabelecer uma rede e/ou comunidade e dela fazer parte: compartilhar informações com os indivíduos ao nosso redor.

O Passei Direto é a base centralizadora das interações entre os usuários, sendo o principal elo entre eles, uma vez que não há interação entre todos os usuários simultaneamente nem há uma liderança representativa que os reúna. Portanto, a relação vai sendo criada a partir das interações que se estabelecem a partir de pequenas ações, tais como compartilhar publicações e criar e/ou usar tags que as representem, as organizem e as tornem visíveis para os demais usuários da rede.

Assim, as tags representam as publicações dentro da rede e também funcionam como elos entre pessoas com interesses comuns. Aliás, a prática de compartilhar informações está relacionada a ser ou se sentir parte integrante de um grupo, uma vez que para fazer parte dele deve existir essa colaboratividade.

Sobre os 30 documentos analisados do grupo @Biblioteconomia, sistematizamos o Quadro 1, a seguir.

Quadro 1 - Quantitativo de documentos e tags atribuídas em @Biblioteconomia.

\begin{tabular}{|c|c|}
\hline $\begin{array}{c}\text { Quantidade de } \\
\text { Tags Atribuidas }\end{array}$ & $\begin{array}{c}\text { Quantidade de } \\
\text { Documentos }\end{array}$ \\
\hline 0 & 2 \\
\hline $\mathbf{1}$ & $\mathbf{1 0}$ \\
\hline $\mathbf{2}$ & $\mathbf{5}$ \\
\hline$\underline{\mathbf{3}}$ & $\underline{\mathbf{8}}$ \\
\hline$\underline{\mathbf{4}}$ & $\underline{\mathbf{3}}$ \\
\hline$\underline{\mathbf{5}}$ & $\underline{1}$ \\
\hline 6 & 1 \\
\hline
\end{tabular}

Fonte: A Pesquisa.

Como pode ser visto nos itens destacados apenas em negrito no quadro 1, 26 documentos possuem de 1 a 4 tags atribuídas, totalizando a maioria dos materiais. Desses 26 
documentos, 11 possuem de 3 a 4 tags atribuídas, como pode ser visto nos itens destacados em negrito e sublinhado. Há um documento que possui 5 tags atribuídas, como pode ser visto no item destacado apenas em sublinhado.

Quer dizer, dos 30 documentos analisados, apenas 12 foram representados com a quantidade média de termos utilizados nas palavras-chave de trabalhos acadêmicos, artigos científicos etc., representando pouco menos da metade dos documentos.

Nas tags atribuídas aos 30 documentos analisados foram observadas algumas características, tais como: erros de grafia/digitação (exemplos: \#PLANEJAMENTO DEBIBLIOTECAS - tag atribuída ao documento 8 e \#biblioteconima - tag atribuída ao documento 23); algumas palavras estão grafadas com e outras sem uso de acentuação, inclusive a mesma palavra na mesma tag (exemplo: \#memoria e memória coletiva - tag atribuída ao documento 7); algumas tags apresentam espaços em branco, outras usam hífen e outras não usam nenhum tipo de caractere para separar as palavras de um termo composto (exemplos: \#Formação e Desenvolvimento de Coleções - tag atribuída ao documento 10, \#Leitura-esociedade - tag atribuída ao documento 22 e \#GestãodaInformação - tag atribuída ao documento 23); uma única tag apresenta termos diferentes, que não necessariamente formam um termo composto, mas traz termos que poderiam ter sido separados pelo uso de tags diferentes (exemplos: \#representação temática classificação biblioteconomia - tag atribuída ao documento 1 e \#Catalogação.Representação. - tag atribuída ao documento 27); uso duplicado do símbolo cerquilha (\#) (exemplo: \#\#Gestão-do- conhecimento - tag atribuída ao documento 26).

Além disso, a partir dos dados coletados foi possível constatar que a maioria das tags atribuídas aos documentos são generalistas em relação aos assuntos escolhidos para representálos, o que diminui a especificidade da indexação e aumenta a quantidade de documentos recuperados por essas tags.

Em alguns documentos foi possível observar que nem todas as tags atribuídas se referiam ao assunto/conteúdo daquele documento. Como, por exemplo, a tag \#JAQUE atribuída ao documento 3, que representa o nome da usuária que publicou o documento. Em outros documentos foi possível observar que tags como \#UNIASSELVI (atribuída aos documentos 14 e 17) foram usadas não necessariamente para representar o assunto do material, mas como meio de reunir os materiais que estão relacionados com essa instituição de ensino.

É relevante apontar que apenas dois documentos não tiveram nenhuma tag atribuída, o que significa que os demais 28 documentos tiveram sua descrição de assuntos e recuperação enriquecidas pelo uso das tags. 
Sobre os 30 documentos analisados do grupo @ Gestão da Informação, sistematizamos o Quadro 2, a seguir.

Quadro 2 - Quantitativo de documentos e tags atribuídas em @ Gestão da Informação.

\begin{tabular}{|c|c|}
\hline $\begin{array}{c}\text { Quantidade de } \\
\text { Tags Atribuídas }\end{array}$ & $\begin{array}{c}\text { Quantidade de } \\
\text { Documentos }\end{array}$ \\
\hline 0 & 1 \\
\hline 1 & 1 \\
\hline 2 & 1 \\
\hline$\underline{\mathbf{3}}$ & $\underline{\mathbf{9}}$ \\
\hline$\underline{\mathbf{4}}$ & $\underline{\mathbf{5}}$ \\
\hline$\underline{\mathbf{5}}$ & $\underline{\mathbf{6}}$ \\
\hline 6 & 1 \\
\hline 7 & 1 \\
\hline 11 & 1 \\
\hline 12 & 1 \\
\hline 15 & 1 \\
\hline 19 & 1 \\
\hline 23 & 1 \\
\hline
\end{tabular}

Fonte: A Pesquisa.

Como pode ser visto nos itens destacados em negrito e sublinhado no Quadro 2, 20 documentos possuem de 3 a 5 tags atribuídas, totalizando a maioria dos materiais. Quer dizer, dos 30 documentos analisados, 20 foram representados com a quantidade média de termos utilizados nas palavras-chave de trabalhos acadêmicos, artigos científicos etc., representando mais da metade dos documentos.

Nas tags atribuídas aos 30 documentos analisados foram observadas algumas características, tais como: erros de grafia/digitação (exemplo: \#Púbilca - tag atribuída ao documento 18 e \#gestão-do-conheciemnto - tag atribuída ao documento 24); algumas palavras estão grafadas com e outras sem uso de acentuação (exemplo: \#Organizações-Públicas - tag atribuída ao documento 9 e \#sistemas-de-informacao - tag atribuída ao documento 29); algumas tags apresentam espaços em branco, outras usam hífen e outras não usam nenhum tipo de caractere para separar as palavras de um termo composto (exemplos: \#Gestãoda Tecnologia da Informação - tag atribuída ao documento 2, \#Características-dos-Documentos - tag atribuída ao documento 11 e \#GestãodaInformação - tag atribuída ao documento 6); uma única tag apresenta termos diferentes, que não necessariamente formam um termo composto, mas traz termos que poderiam ter sido separados pelo uso de tags diferentes (exemplos: \#Tomada de decisão Sistemas de informação - tag atribuída ao documento 1); uso duplicado do símbolo cerquilha (\#), seja no início ou no final da tag (exemplos: \#\#excel - tag atribuída ao documento 7 e \#PROVA\# - tag atribuída ao documento 4); uso de outros símbolos nas tags, como traço baixo/underline (_) e ponto final (exemplos: \#Análise_Desenvolvimento_de_Sis - tag atribuída 
ao documento 4 e \#microfilmar. - tag atribuída ao documento 26); palavras incompletas na composição das tags (exemplos: \#Gestão-da- Tecnologia-da-Inform - tag atribuída ao documento 24 e \#Gestão-da- Informação-e-Documen - tag atribuída ao documento 25).

Além disso, a partir dos dados coletados foi possível constatar que a maioria das tags atribuídas aos documentos são generalistas em relação aos assuntos escolhidos para representálos, o que diminui a especificidade da indexação e aumenta a quantidade de documentos recuperados por essas tags.

Algumas tags apresentam mais de uma característica em sua apresentação, uma vez que as características apontadas acima não são categorias excludentes. Por exemplo, na mesma tag pode haver erros de grafia/digitação, uso de outros símbolos nas tags e palavras incompletas em sua composição etc. Assim como pode acontecer de a tag não apresentar nenhuma característica que dificulte seu uso enquanto instrumento de organização e recuperação de informações no sistema.

$\mathrm{Na}$ análise dos 30 documentos desse último grupo é importante ressaltar que houve casos em que a quantidade de tags atribuídas foi muito maior do que a média ( 3 a 5 termos). Dos 30 documentos analisados, 5 tiveram entre 11 e 23 tags atribuídas, indicando usuários que acreditam que quanto mais tags um documento tiver, maiores serão as suas chances de busca/recuperação, uma vez que há diversos pontos de acesso pelo qual esse documento pode ser procurado e encontrado.

Também é relevante apontar que apenas um documento não teve nenhuma tag atribuída, o que significa que os demais 29 documentos tiveram sua descrição de assuntos e recuperação enriquecidas pelo uso das tags.

Sobre os 30 documentos analisados do grupo @Ciência da Informação, sistematizamos o Quadro 3, a seguir.

Quadro 3 - Quantitativo de documentos e tags atribuídas em @ Ciência da Informação.

\begin{tabular}{|c|c|}
\hline $\begin{array}{c}\text { Quantidade de } \\
\text { Tags Atribuídas }\end{array}$ & $\begin{array}{c}\text { Quantidade de } \\
\text { Documentos }\end{array}$ \\
\hline 0 & 1 \\
\hline $\mathbf{1}$ & $\mathbf{4}$ \\
\hline $\mathbf{2}$ & $\mathbf{4}$ \\
\hline$\underline{\mathbf{3}}$ & $\underline{\mathbf{7}}$ \\
\hline$\underline{\mathbf{4}}$ & $\underline{\mathbf{4}}$ \\
\hline$\underline{\mathbf{5}}$ & $\underline{\mathbf{5}}$ \\
\hline 6 & 1 \\
\hline 7 & 2 \\
\hline 8 & 1 \\
\hline 10 & 1 \\
\hline
\end{tabular}

Fonte: A Pesquisa. 
Como pode ser visto nos itens destacados apenas em negrito no quadro 3, 24 documentos possuem de 1 a 5 tags atribuídas, totalizando a maioria dos materiais. Desses 24 documentos, 16 possuem de 3 a 5 tags atribuídas, como pode ser visto nos itens destacados em negrito e sublinhado, totalizando pouco mais da metade dos materiais. Quer dizer, a maioria dos documentos foram representados com a quantidade média de termos utilizados nas palavras-chave de trabalhos acadêmicos, artigos científicos etc.

Nas tags atribuídas aos 30 documentos analisados foram observadas algumas características, tais como: erros de grafia/digitação (exemplos: \#concervação - tag atribuída ao documento 6 e \#informção - tag atribuída ao documento 10); algumas palavras estão grafadas com e outras sem uso de acentuação (exemplos: \#catalogação - tag atribuída ao documento 26 e \#relacao - tag atribuída ao documento 20); algumas tags apresentam espaços em branco, outras usam hífen e outras não usam nenhum tipo de caractere para separar as palavras de um termo composto (exemplos: \#fluxo de informação - tag atribuída ao documento 3, \#identidadecultural - tag atribuída ao documento 4 e \#museudearte - tag atribuída ao documento 7); uma única tag apresenta termos diferentes, que não necessariamente formam um termo composto, mas traz termos que poderiam ter sido separados pelo uso de tags diferentes (exemplo: \#ciencia TCC portfólio trabalho museu - tag atribuída ao documento 2); alguns termos são apresentados de maneiras diferentes, em tags diferentes, apesar de representarem o mesmo assunto (exemplos: \#CiênciadaInformação - tag atribuída ao documento 1, \#Ciencia-da-Informacao tag atribuída ao documento 5 e \#CiênciaInformação - tag atribuída ao documento 16).

Além disso, a partir dos dados coletados foi possível constatar que a maioria das tags atribuídas aos documentos são generalistas em relação aos assuntos escolhidos para representálos, o que diminui a especificidade da indexação e aumenta a quantidade de documentos recuperados por essas tags.

É relevante apontar que apenas um documento não teve nenhuma tag atribuída, o que significa que os demais 29 documentos tiveram sua descrição de assuntos e recuperação enriquecidas pelo uso das tags.

\section{CONSIDERAÇÕES FINAIS}

À guisa de conclusão, destacamos que dos 90 documentos que foram analisados nos 3 grupos, 48 foram representados com a quantidade média de termos utilizados nas palavraschave de trabalhos acadêmicos, artigos científicos etc. (de 3 a 5 termos), representando pouco mais da metade dos documentos. 
Desses 48 documentos, 16 são do grupo @Ciência da Informação, 12 são do grupo @ Biblioteconomia e 20 são do grupo @ Gestão da Informação. Ou seja, nos grupos @Ciência da Informação e @Gestão da Informação mais da metade dos documentos estavam representados segundo o parâmetro mencionado no parágrafo acima.

É muito relevante pontuar que desses 90 documentos analisados apenas 4 não estavam indexados com nenhuma tag: um documento do grupo @ Ciência da Informação, 2 documentos do grupo @Biblioteconomia e um documento do grupo @ Gestão da Informação. Ou seja, em apenas $4 \%$ do total de documentos analisados a folksonomia não foi utilizada enquanto ferramenta de apoio nos grupos colaborativos.

Os demais 38 documentos possuem tags atribuídas, onde foram observadas as seguintes características: a) desses 38 documentos, 25 estavam com a quantidade média de termos abaixo do parâmetro de 3 a 5 termos atribuídos - os usuários utilizaram apenas uma ou duas tags para indexar os documentos; b) desses 38 documentos, 13 estavam com a quantidade média de termos acima do parâmetro de 3 a 5 termos atribuídos - os usuários utilizaram de 6 a 23 tags para indexar os documentos.

Sendo os usuários os responsáveis pela indexação, não são impostas regras, logo, não há controle do alfabeto e idioma usados, da ambiguidade, dos sinônimos ou homônimos, do plural ou singular, das palavras simples ou compostas, dos termos inexatos, sem sentido ou que só tem significado para um usuário ou um grupo específico de usuários que o utilizou, que geralmente não percebem essas variações. Também é importante saber que, como em toda tradução, na indexação também há perda de informações, já que é improvável que um documento seja representado com "exatidão" e que seja unânime entre os usuários que os termos atribuídos foram os mais adequados.

Ao responder à questão desta pesquisa destacamos que a folksonomia é sim uma ferramenta de apoio em grupos colaborativos no Passei Direto e, conforme a análise feita ao atingir o objetivo geral desta pesquisa, consideramos que:

a) a escolha das tags pode ocorrer individualmente ou por senso comum, por meio do uso das tags populares já incorporadas ao sistema e sugeridas por ele, mas o fato de o sistema sugerir tags não implica necessariamente na sua adoção, então, a sua utilização variará entre os usuários, uma vez que somos influenciados pelo meio, mas também escolhemos o meio com o qual queremos nos relacionar.

b) ao utilizarem as tags, os usuários não são motivados apenas por necessidades pessoais (aqueles que querem apenas organizar as próprias publicações), mas também por interesses sociais (aqueles que querem compartilhar as suas publicações e buscar por outras). 
Portanto, a classificação social é uma inovação que explora o potencial das redes sociais na organização e no compartilhamento de informações, agregando as manifestações da linguagem contextualizada dos usuários em colaboração. 


\section{REFERÊNCIAS}

ALCARÁ, A. R. et al. Fatores que influenciam o compartilhamento da informação e do conhecimento. Perspectivas em Ciência da Informação, Belo Horizonte, v. 14, n. 1, p. 170191, 2009. Disponível em: https://www.scielo.br/pdf/pci/v14n1/v14n1a12.pdf. Acesso em: 23 fev. 2021.

AMORIM, F. B.; TOMAÉL, M. I. O uso de sistemas de informação e seus reflexos na cultura organizacional e no compartilhamento de informações. Perspectivas em Gestão \& Conhecimento, João Pessoa, v. 1, n. 1, p. 74-91, 2011. Disponível em: https://periodicos.ufpb.br/ojs2/index.php/pgc/article/view/9938/5620. Acesso em: 23 fev. 2021.

ARAÚJO, C. A. A. Fundamentos teóricos da classificação. Encontros Bibli: revista eletrônica de Biblioteconomia e Ciência da Informação, Florianópolis, v. 11, n. 22, p. 117 140, 2006. Disponível em: https://periodicos.ufsc.br/index.php/eb/article/view/15182924.2006v11n22p117/368. Acesso em: 23 fev. 2021.

ARBOIT, A. E. Epistemologia da documentação: provocações necessárias. Ágora: Arquivologia em debate, Florianópolis, v. 24, n. 48, p. 382-388, 2014. Disponível em: https://agora.emnuvens.com.br/ra/article/view/470/pdf_36. Acesso em: 23 fev. 2021.

ASSIS, J. de; MOURA, M. A. Folksonomia: a linguagem das tags. Encontros Bibli: revista eletrônica de Biblioteconomia e Ciência da Informação, Florianópolis, v. 18, n. 36, p. 85106, 2013. Disponível em: https://periodicos.ufsc.br/index.php/eb/article/view/15182924.2013v18n36p85/24523. Acesso em: 23 fev. 2021.

BULLARD, J. Curated folksonomies: three implementations of structure through human judgment. Knowledge Organization, Würsburg, v. 45, n. 8, p. 643-652, 2018.

CAMPOS, M. L. A.; GOMES, H. E. Taxonomia e classificação: a categorização como princípio. In: ENCONTRO NACIONAL DE PESQUISA EM CIÊNCIA DA INFORMAÇÃO, 8., 2007, Salvador. Anais... Salvador: UFBA, 2007. Disponível em: http://repositorios.questoesemrede.uff.br/repositorios/handle/123456789/159. Acesso em: 23 fev. 2021.

CATARINO, M. E.; BAPTISTA, A. A. Folksonomias: características das etiquetas na descrição de recursos da web. Informação \& Informação, Londrina, v. 14, n. 1 esp., p. 4667, 2009. Disponível em: http://www.uel.br/revistas/uel/index.php/informacao/article/view/3234/3221. Acesso em: 23 fev. 2021.

DÍAZ PIRAQUIVE, F. N.; JOYANES AGUILAR, L.; MEDINA GARCÍA, V. H.

Taxonomía, ontología y folksonomía, ¿qué son y qué beneficios u oportunidades presentan para los usuarios de la web? Revista Universidad y Empresa, Bogotá, v. 8, n. 16, p. 242261, 2009. Disponível em:

https://revistas.urosario.edu.co/index.php/empresa/article/view/1079/977. Acesso em: 23 fev. 2021. 
GARCÍA GUTIÉRREZ, A. Epistemologia de la documentación. Barcelona: Stonberg, 2011.

MARCONI, M. A.; LAKATOS, E. M. Fundamentos da metodologia científica. 5. ed. São Paulo: Atlas, 2003.

MARTELETO, R. M. A metodologia de análise de redes sociais (ARS). In: VALENTIM, M. L. P. (Org.). Métodos qualitativos de pesquisa em Ciência da Informação. São Paulo: Polis, 2005. p. 81-100.

PASSEI DIRETO S/A. Passei Direto. Rio de Janeiro, c2021. Disponível em: https://www.passeidireto.com/. Acesso em: 19 jan. 2021.

PÉREZ SANCHIDRIÁN, E.; CAMPOS POSADA, R.; CAMPOS POSADA; G. E. Etiquetado social: un modelo de representación de la información en la blogosfera. Biblios, Lima, n. 56, p. 19- 27, 2014. Disponível em:

https://biblios.pitt.edu/ojs/index.php/biblios/article/view/187/207. Acesso em: 23 fev. 2021.

QIN, J. Folksonomies and taxonomies: where the two can meet. Washington, DC: NKOS Workshop, 2008.

SANTOS, H. P. Etiquetagem e folksonomia: o usuário e sua motivação para organizar e compartilhar informação na Web 2.0. Perspectivas em Ciência da Informação, Belo Horizonte, v. 18, n. 2, p. 91-104, 2013. Disponível em:

https://www.scielo.br/pdf/pci/v18n2/07.pdf. Acesso em: 23 fev. 2021.

SECO, L. F. C.; SANTOS, Z. P.; BARTALO, L. Comportamento informacional e compartilhamento da informação no Instagram. Revista ACB: Biblioteconomia em Santa Catarina, São José, v. 21, n. 1, p. 46-60, 2016. Disponível em: https://revista.acbsc.org.br/racb/article/view/1144/pdf. Acesso em: 23 fev. 2021.

SMIRAGLIA, R. The elements of knowledge organization. New York: Springer, 2014.

STREHL, L. As folksonomias entre os conceitos e os pontos de acesso: as funções de descritores, citações e marcadores nos sistemas de recuperação da informação. Perspectivas em Ciência da Informação, Belo Horizonte, v. 16, n. 2, p. 101-114, 2011. Disponível em: http://portaldeperiodicos.eci.ufmg.br/index.php/pci/article/view/908/926. Acesso em: 23 fev. 2021.

TAYLOR, A.; JOUDREY, D. N. The information organization. Westport: Libraries Unlimited, 2009.

TOMAÉL, M. I; MARTELETO, R. M. Do compartilhamento da informação ao conhecimento coletivo. In: ENCONTRO NACIONAL DE PESQUISA EM CIÊNCIA DA INFORMAÇÃO, 7., 2006, Marília. Anais... Marília: ANCIB, 2006. Disponível em: http://repositorios.questoesemrede.uff.br/repositorios/handle/123456789/1260?show=full. Acesso em: 23 fev. 2021.

TRANT, J. Studying social tagging and folksonomy: a review and framework. Journal of Digital Information, Austin, v. 10, n. 1, p. 1-44, 2009. Disponível em:

https://journals.tdl.org/jodi/index.php/jodi/article/view/269. Acesso em: 23 fev. 2021. 
VIERA, A. F. G.; GARRIDO, I. S. Folksonomia como uma estratégia para Recuperação Colaborativa da Informação. DataGramaZero, Rio de Janeiro, v. 12, n. 2, não paginado, 2011. Disponível em: https://brapci.inf.br/index.php/res/v/7336. Acesso em: 23 fev. 2021.

VIGNOLI, R. G.; ALMEIDA, P. O. P. de; CATARINO, M. E. Folksonomias como ferramenta da organização e representação da informação. Revista Digital de

Biblioteconomia e Ciência da Informação, Campinas, v. 12, n. 2, p. 120-135, 2014.

Disponível em:

https://periodicos.sbu.unicamp.br/ojs/index.php/rdbci/article/view/1606/pdf_65. Acesso em: 23 fev. 2021. 